\title{
Autoantibodies to Type VII Collagen Recognize Epitopes in a Fibronectin-Like Region of the Noncollagenous (NC1) Domain
}

\author{
W. Ray Gammon, Dédée F. Murrell, Mark W. Jenison, Karen M. Padilla, Phillip S. Prisayanh, Drew A. Jones, \\ Robert A. Briggaman, and Stephen W. Hunt III \\ Department of Dermatology, University of North Carolina School of Medicine; and Departments of Medicine and Microbiology and \\ Immunology and the Program in Molecular Biology and Biotechnology, University of North Carolina School of Medicine, Chapel \\ Hill, North Carolina, U.S.A.
}

\begin{abstract}
Autoantibodies to type VII collagen are characteristic of the blistering diseases epidermolysis bullosa acquisita and bullous systemic lupus erythematosus (SLE). Blisters in those diseases are due to defective adhesion of the lamina densa subregion of the epithelial basement membrane to the underlying dermis. Previous studies indicating that type VII collagen contributes to lamina densa-dermal adhesion by cross-linking lamina densa and dermal matrix proteins suggests that autoantibodies may contribute to blisters by interfering with type VII collagen function. That hypothesis is supported by previous studies showing autoantibodies from a small number of epidermolysis bullosa acquisita patients recognize proteolytic
\end{abstract}

fragments containing the $145-\mathrm{kD}$ noncollagenous domain of type VII collagen. In this study, we examined reactivity of autoantibodies from a large number of epidermolysis bullosa acquisita and bullous SLE patients with fusion proteins representing most of the noncollagenous domain of type VII collagen and that those regions are homologous to type III repeats of fibronectin. These results suggest autoantibodies binding to fibronectin homology regions within the $145-\mathrm{kD}$ noncollagenous domain may interfere with the adhesion function of type VII collagen and contribute to lamina densa - dermal dysadhesion in epidermolysis bullous acquisita and bullous SLE. J Invest Dermatol 100:618-622, 1993

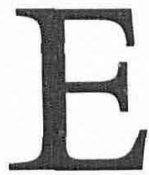
pidermolysis bullosa acquisita (EBA) and bullous systemic lupus erythematosus (SLE) are relatively rare autoimmune blistering diseases of stratified squamous epithelia (reviewed in $[1,2]$ ). Both diseases are characterized by circulating and tissue-bound IgG autoantibodies to the epithelial basement membrane. Previous studies have shown that basement membrane antibodies in EBA react with type VII collagen (C7), and indicate that basement membrane antibodies in bullous SLE have the same specificity $[3,4]$. Histologic studies have shown that blisters in these diseases result from separation of the epidermis from the dermis at the level of the epithelial basement membrane $[1,2]$. Electron microscopic studies of the epithelial basement membrane region show that epidermal-dermal separation is

Manuscript received August 21, 1992; accepted for publication November 2, 1992.

Reprint requests to: Dr. W.R. Gammon, Department of Dermatology, CB 7600, 137 UNC Hospitals, Chapel Hill, NC 27514.

Abbreviations:

BSA: bovine serum albumin

C7: type VII collagen

EBA: epidermolysis bullosa acquisita

ELISA: enzyme-linked immunosorbent assay

Fn III: type III fibronectin repeats

IPTG: isopropyl-beta-D-thiogalactopyranoside

NC1: $145-\mathrm{kD}$ noncollagenous domain/type VII collagen

PBS: phosphate-buffered saline

PCR: polymerase chain reaction

SDS-PAGE: sodium dodecylsulfate-polyacrylamide gel electrophoresis

SLE: systemic lupus erythematosus

vWf: von Willebrand factor due to dysadhesion of the lamina densa subregion of the basement membrane from the upper dermis [1,2]. The increasing evidence that $\mathrm{C} 7$ contributes to normal lamina densa-dermal adhesion suggests $\mathrm{C} 7$ autoantibodies may contribute to blisters in EBA and bullous SLE by interfering with C7 function.

Collagen VII is an epithelial basement membrane-restricted protein composed of three identical alpha chains, each consisting of an amino-terminal $145-\mathrm{kDa}$ noncollagenous (NC1) domain and a 145-kDa carboxyl-terminal collagenous domain [5,6]. Molecules of C7 aggregate in vivo to form morphologically distinctive fibrillar structures called anchoring fibrils $[5,7,8]$. The ends of anchoring fibrils associate with the lamina densa and with dermal structures called anchoring plaques, resulting in the formation of a sub-lamina densa fibrillar network that appears to "anchor" the lamina densa to the dermis [9]. A role for C7 in lamina densa-dermal adherence is supported by an association between defective lamina densadermal adhesion and abnormal expression of anchoring fibrils and immunoreactive C7 in patients with inherited forms of dystrophic epidermolysis bullosa [10]. Recent gene mapping studies indicate that these diseases are due to a defect in the C7 gene [11]. Interestingly, the clinical, pathologic, and ultrastructural features of skin lesions in patients with dominantly inherited dystrophic epidermolysis bullosa closely resemble those features in some EBA patients $[1,10]$.

The adherence role for C7, evidence that a genetic defect in C7 contributes to lamina densa-dermal dysadhesion in dystrophic forms of EB, and similarities between patients with dystrophic epidermolysis bullosa and patients with autoantibodies to C7 suggests the autoantibodies may contribute to lamina densa-dermal dysadhesion by interfering with the adherence function of C7. That hypothesis is supported by a recent study showing that C7 antibod- 

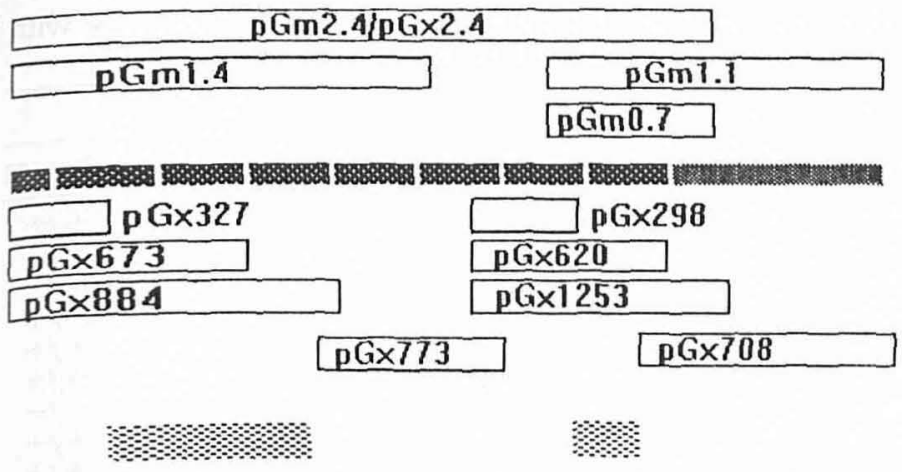

Figure 1. Schematic of the CVII-1 cDNA showing $7 \frac{1}{2}$ Fn repeats ( consisting of approximately 90 amino acids per repeat at the $5^{\prime}$ end, and a

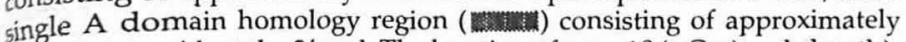
190 amino acids at the $3^{\prime}$ end. The location of gene $10(\mathrm{pGm})$ and glutathione transferase $(\mathrm{pGx}$ ) fusion proteins relative to CVII-1 homology regions is shown ( $\square$ ) above and below the CVII-1 homology regions. is the bottom of the figure indicates regions recognized by most autoimane sera. The corresponding beginning $\left(5^{\prime}\right)$ and ending $\left(3^{\prime}\right)$ nucleotides mune sch of the fusion proteins are as follows: pGm2.4 and pGx2.4 (nts 1-2255); pGm1.4 (nts 1-1250); pGm1.1 (nts 1644-2661); pGm0.7 (nts 1644-2255); pGx327 (nts 1-327); pGx673 (nts 1-673); pGx884 (nts 1-884); pGx773 (nts 868-1641); pGx298 (nts 1372-1665); pGx620 (nts 1372-1987); pGx1253 (nts 1372-2273), and pGx708 (nts 1901-2661).

ies from several patients with EBA react with proteolytic fragments that contain the NC1 but not the collagenous domain of C7 [3]. The NC1 domain is the region of $\mathrm{C} 7$ that appears to link anchoring fibrils to the lamina densa and the dermis by interacting with lamina densa and dermal matrix proteins such as type IV collagen $[9,12,13]$. A role for the NC1 domain in mediating interactions between C7 and other matrix proteins suggests $C 7$ autoantibodies might contribute to lamina densa-dermal dysadhesion by targeting functional regions of the NC1 domain. In this study, epitope regions recognized by antibodies from 12 EBA and bullous SLE patients were mapped using fusion proteins corresponding to most of the NC1 domain of C7.

\section{MATERIALS AND METHODS}

Antibodies Sera containing autoantibodies to the epithelial basement membrane of stratified squamous epithelia were obtained from seven EBA and five bullous SLE patients. Titers of the antibodies were determined by indirect immunofluorescence on $1.0 \mathrm{M}$ $\mathrm{NaCl}$-split normal human skin as previously described and ranged between $1: 80$ and $1: 1280$ [14]. All of the sera contained antibodies to the dermal side of split skin by indirect immunofluorescence and reacted with tissue C7 or proC7 by Western immunoblotting or immunoprecipitation as previously described $[13,15]$. Control sera were obtained from three EBA patients without detectable circulating anti-basement membrane antibodies, three patients with bullous pemphigoid who have anti-basement membrane antibodies that target hemidesmosome-associated antigens, three patients with active SLE, and three normal humans. A previously characterized murine monoclonal antibody, L3d, that reacts with the NC1 domain of C7 was used as an additional control [16].

cDNA and DNA Fragments A previously described partial C7 cDNA (CVII-1) was used as a source of DNA fragments [13]. CVII1 (2661 nts) encodes an estimated $75 \%$ of NC1 beginning downstream of the $5^{\prime}$ start site and ending at the beginning of the collagenous domain. It encodes $\left(5^{\prime}>3^{\prime}\right) 7 \frac{1}{2}$ sequential fibronectin III (FN III) repeats of 90 amino acids each followed by a von Willebrand factor (vWf) A-like domain homology region of 190 amino acids (Fig 1) [13]. DNA corresponding to different regions of CVII-1 was prepared for cloning by restriction endonuclease digestion, exonuclease III digestion using the Erase-a-Base System (Promega Corp), and DNA amplification by the polymerase chain reaction (PCR) [17-19].

Fusion Proteins DNA fragments corresponding to indicated regions of the CVII-1 cDNA (Fig 1) were cloned into pGEMEX1 (Promega Corp) and pGEX-2T (Pharmacia) respectively using instructions provided by the suppliers. pGEMEX 1 gene $10(\mathrm{pGm})$ and PGEX-2T glutathione S-transferase ( $\mathrm{pGx}$ ) fusion proteins were expressed in JM109(DE3) Escherichia coli cells following addition of isopropyl-beta-D-thiogalactopyranoside (IPTG) to log-phase cultures. Recombinant clones were screened by SDS-PAGE of bacterial lysates and by immunoblotting with a rabbit antibody to the pGEMEX1 gene 10 protein (Novagen); a monoclonal antibody (L3d) to the NC1 domain of C7; and a reference EBA serum, EOO7, containing high-titer antibodies to C7 and CVII-1 fusion protein [13]. Gene 10 proteins were screened for expression of C7 and/or gene 10 epitopes at or near the predicted mass. Glutathione transferase proteins were affinity purified by absorption on glutathione Sepharose (Pharmacia) and assayed by SDS-PAGE and immunoblotting
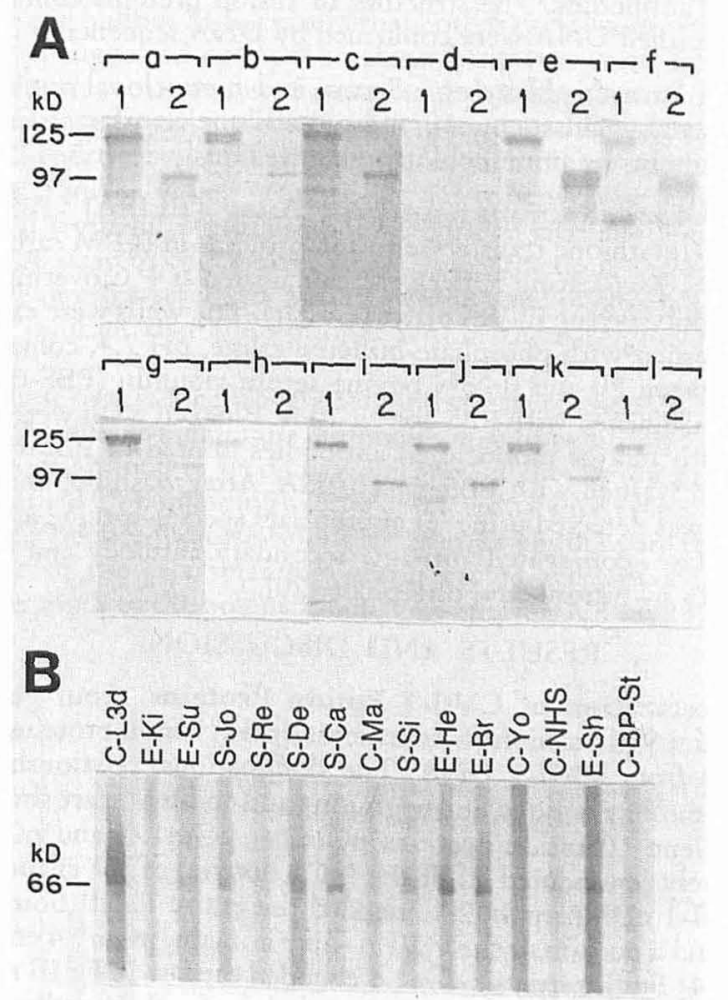

Figure 2. $A$ : Western blots of sera $(\mathrm{a}-\mathrm{l})$ containing $\mathrm{C} 7$ antibodies against pGm2.4 (all lanes labeled " 1 ") and pGm1.4 (all lanes labeled "2"). Top row: $a-f$ correspond to sera E-Ki, E-He, S-Jo, E-Te, E-Br, and S-Ra, respectively. Bottom row: $g-l$ correspond to sera S-Ca, E-Si, S-Re, E-Su, E-Sh, and S-De, respectively. Sera with a basement membrane antibody titer of greater than $1: 100$ by indirect immunofluorescence were used at a dilution of $1: 100$ and Sera with a titer of less than $1: 100$ were used at a dilution of $1: 20$. Control sera (not shown) did not label either the 125 or $97 \mathrm{kD}$ bands. B: Western blots against fusion protein pGm1.1 (66 kD). EBA and bullous SLE sera containing basement membrane antibodies are designated by $E$ and $S$ respectively. Control (C) sera were negative for $C 7$ antibodies. C-Ma and C-Yo are two EBA sera without basement membrane antibodies by indirect immunofluorescence. C-BP-St is a bullous pemphigoid serum with basement membrane antibodies against the bullous pemphigoid antigen (titer $>1: 640$ ). C-L3d is a monoclonal antibody reactive with the $\mathrm{NCl}$ domain of $\mathrm{C} 7$. Control sera were used at a dilution of $1: 20$. Other sera were used at dilutions of $1: 20$ or $1: 100$. Faint staining of $\mathrm{pGm} 1.1$ could occasionally be observed with $1: 20$ dilutions of normal human sera, e.g., C-NHS; therefore, reactions were interpreted as positive only if staining was stronger than C-NHS. 
Table I. EBA (E) and Bullous SLE (S) Serum Reactivity with CVII-1 Fusion Proteins ${ }^{a}$

\begin{tabular}{|c|c|c|c|}
\hline Serum & pGm2.4 & pGm1. $4^{c}$ & pGm1.1 ${ }^{c}$ \\
\hline E-Ki & $+/+^{b}$ & + & + \\
\hline E-He & $+/+$ & + & + \\
\hline $\mathrm{E}-\mathrm{Br}$ & $+1+$ & + & + \\
\hline E-Su & $+1+$ & + & + \\
\hline E-Si & $+1+$ & - & + \\
\hline E-Sh & $+1+$ & - & + \\
\hline E-Te & $-1-$ & - & - \\
\hline S-De & $+1+$ & - & + \\
\hline S-Ca & $+/+$ & + & + \\
\hline S-Ra & $+1+$ & + & + \\
\hline S-Jo & $+/ t$ & + & + \\
\hline S-Re & $+/ t$ & + & + \\
\hline
\end{tabular}

+ , positive; - , negative.

${ }^{b}$ Blotting results/ELISA results.

'Blotting results only.

with $\mathrm{C7}$ antibodies. The structure of fusion proteins containing PCR-amplified DNA were confirmed by DNA sequencing [19].

Western Immunoblotting Serum and monoclonal antibodies were assayed against gene 10 and glutathione transferase CVII-1 fusion proteins by immunoblotting as previously described [13].

Enzyme-Linked Immunosorbant Assay (ELISA) Affinitypurified glutathione transferase fusion proteins in $0.1 \mathrm{M}$ carbonate buffer, $\mathrm{pH} 9.6$ (coating buffer), were incubated at $4^{\circ} \mathrm{C}$ overnight in 96-well polystyrene ELISA plates (Costar). The wells were exhaustively washed with phosphate-buffered saline, $\mathrm{pH} 7.4$, containing $0.05 \%$ tween 20 and $0.25 \%$ bovine serum albumin (PBS-tweenBSA), and blocked with PBS-tween-BSA. Blocked wells were incubated with sera or monoclonal antibodies diluted in PBS-tweenBSA, and washed with PBS-tween-BSA. After washing, antibody binding was detected using an appropriate species-specific alkaline phosphatase-conjugated anti-IgG secondary antibody and developed with p-nitrophenyl phosphate [20].

\section{RESULTS AND DISCUSSION}

Characterization of CVII-1 Fusion Proteins Four gene 10 $(\mathrm{pGm})$ and 9 glutathione S-transferase $(\mathrm{pGx})$ fusion proteins were prepared from CVII-1 DNA. The designations, relationships to NC1 homology regions, and beginning and ending nts are shown in Fig 1. Gene 10 fusion proteins pGm2.4, pGm1.4, and pGm1.1 collectively represented all of the NC1 domain of $\mathrm{C} 7$ encoded by the CVII-1 cDNA. pGm2.4 encoded the entire Fn III homology region and a portion of the $\mathrm{vWf} \mathrm{A}$ - like domain. $\mathrm{pGm} 1.4$ encoded the first $4 \frac{1}{2}$ Fn III repeats. pGm 1.1 encoded the last $1 \frac{1}{2}$ Fn III repeats and all of the A domain. pGm0.7 encoded the first half of the region encoded by pGm1.1. The glutathione transferase fusion proteins included 1) two sets (set I, pGx327, pGx673, pGx884; and set II, pGx298, pGx620, pGx1253) of three partially overlapping fusion proteins representing most of the $\mathrm{N}$ - and C-termini, respectively, of the Fn III homology region; 2) pGx708 corresponding to the A domain; 3) pGx773 corresponding to the Fn III homology region between set I and set II fusion proteins; and 4) pGx2.4 identical to pGm2.4.

EBA and Bullous SLE IgG Antibodies Recognize Fusion Proteins Encoded by Non-Overlapping Regions of the CVII1 cDNA Seven EBA and five bullous SLE sera containing IgG basement membrane antibodies were immunoblotted against pGm2.4, pGm1.4, and pGm1.1 fusion proteins. The results (Fig 2 and Table I) showed that 11 sera (six EBA and five bullous SLE) recognized pGm2.4 and pGm1.1. Sera that recognized pGm2.4 were also found to react by ELISA with pGx2.4 (Table I). Eight of the 11 sera (four EBA and four bullous SLE) also recognized pGm1.4 by blotting. The three sera that blotted pGm1.1 but not pGm1.4 were subsequently found to react by ELISA with set I pGx
Table II. EBA (E) and Bullous SLE (S) Serum Reactivity with CVII-1 Fusion Proteins ${ }^{a}$

\begin{tabular}{|c|c|c|c|c|c|c|}
\hline \multirow[b]{2}{*}{ Sera } & \multicolumn{3}{|c|}{ Set I } & \multicolumn{3}{|c|}{ Set II } \\
\hline & pG $\times 327$ & pGx673 & pGx884 & pG $\times 298$ & pGx620 & pGx1253 \\
\hline E-Ki & $-1-$ & $+1+$ & $+/+$ & $+/+$ & $+/ t$ & $+/ t$ \\
\hline E-He & $-1-$ & $+1+$ & $+1+$ & $-1-$ & $+1+$ & $+1+$ \\
\hline E-Br & & $+1+$ & $+/+$ & & $+/+$ & $+1+$ \\
\hline $\mathrm{E}-\mathrm{Su}$ & $-1-$ & $-1+$ & $+1+$ & $-1-$ & $-1+$ & $-1+$ \\
\hline E-Si & $-1-$ & $-/ N^{b}$ & $-1+$ & $-1-$ & $+1+$ & $+1+$ \\
\hline E-Sh & $-1-$ & $-/ N D$ & $-/ N D$ & & $+/+$ & $+/ t$ \\
\hline E-Te & $-1-$ & $-1-$ & $-1-$ & & $-1-$ & $-1-$ \\
\hline $\begin{array}{l}\text { S-De } \\
\text { S-Ca }\end{array}$ & $-1-$ & $\begin{array}{l}-1- \\
-1-\end{array}$ & $\begin{array}{l}-1+ \\
+1+\end{array}$ & $\begin{array}{l}+ \\
-\end{array}$ & $\begin{array}{l}+/ t \\
+/ t\end{array}$ & $\begin{array}{l}+/ t \\
+/ t\end{array}$ \\
\hline S-Ra & & $-1-$ & $-1+$ & & $+1+$ & $+1+$ \\
\hline S-Jo & & $-1+$ & $+1+$ & & $+/ t$ & $+/ t$ \\
\hline S-Re & $-1-$ & $-/+$ & $+/ t$ & $-1-$ & $-1-$ & $+/ t$ \\
\hline
\end{tabular}

- Blotting results/ELISA results. +, positive; -, negative

b ND, not done.

fusion proteins (Figs 1 and 4 and Table II). indicating that those sera recognized epitopes in $\mathrm{pGm} 1.4$. Serum E-Te (anti-basement membrane antibody titer, $1: 80$ ) and negative control sera did not recognize any of the proteins. Affinity absorption of serum E-Ki on nitrocellulose coated with purified pGx2.4 removed all anti-basement membrane antibody and anti-pGx2.4 activity as assessed by indirect immunofluorescence and ELISA, respectively, and the eluted IgG showed strong anti-basement membrane and anti-pGx2.4 activity (results not shown).

These results show that more than $90 \%$ of EBA and bullous SLE sera containing $\mathrm{C} 7$ antibodies react with fusion particles corresponding to the CVII-1 cDNA. The finding that eight of the sera $(>70 \%$ of reactive sera) recognized fusion proteins ( $\mathrm{pGm1.4}$ and pGm1.1) containing non-overlapping sequences indicates that at least two regions within NC1 are recognized by most EBA and bullous SLE sera. The absence of reactivity by serum E-Te indicates there may be additional epitopes outside the region encoded by CVII-1 or that other epitopes may be dependent on confirmational or post-translational modifications not present in these fusion proteins. The finding that anti-basement membrane antibodies could be completely absorbed from the high-titer (1:640) serum E-Ki with $\mathrm{pG \times 2.4}$ indicates that $\mathrm{pG \times 2.4}$ contains all the major epitopes recognized by circulating $\mathrm{C} 7$ antibodies from that patient and that post-translational changes are not necessary for the formation of those epitopes.

Epitopes Recognized by EBA and Bullous SLE Antibodies Consist of Fn III Sequences To further characterize regions of NC1 recognized by C7 antibodies, we tested EBA and bullous SLE sera for reactivity against fusion proteins from sets I (nts $1-884$ ) and II (nts 1372-2273), pGx 773 (nts 868-1641) and pGx708 (nts

Table III. EBA (E) and Bullous SLE (S) Serum Reactivity with CVII-1 Fusion Proteins ${ }^{a}$

\begin{tabular}{lcc}
\hline Sera & pGx773 & pGx708 \\
\hline E-Ki & $-/-$ & $-/-$ \\
E-He & $-/-$ & $-/-$ \\
E-Br & $-/-$ & $-/-$ \\
E-Su & ND $/-$ & $-/-$ \\
E-Si & $-/-$ & $-/-$ \\
E-Sh & $-/-$ & $-/-$ \\
E-Te & $-/-$ & $-/-$ \\
S-De & $-/+$ & $-/-$ \\
S-Ca & $-/-$ & $-/-$ \\
S-Ra & $-/-$ & $-/-$ \\
S-Jo & $-/+$ & $-/-$ \\
S-Re & ND $/-$ & $-/-$
\end{tabular}

a Blotting results/ELISA results. + , positive; - , negative. 


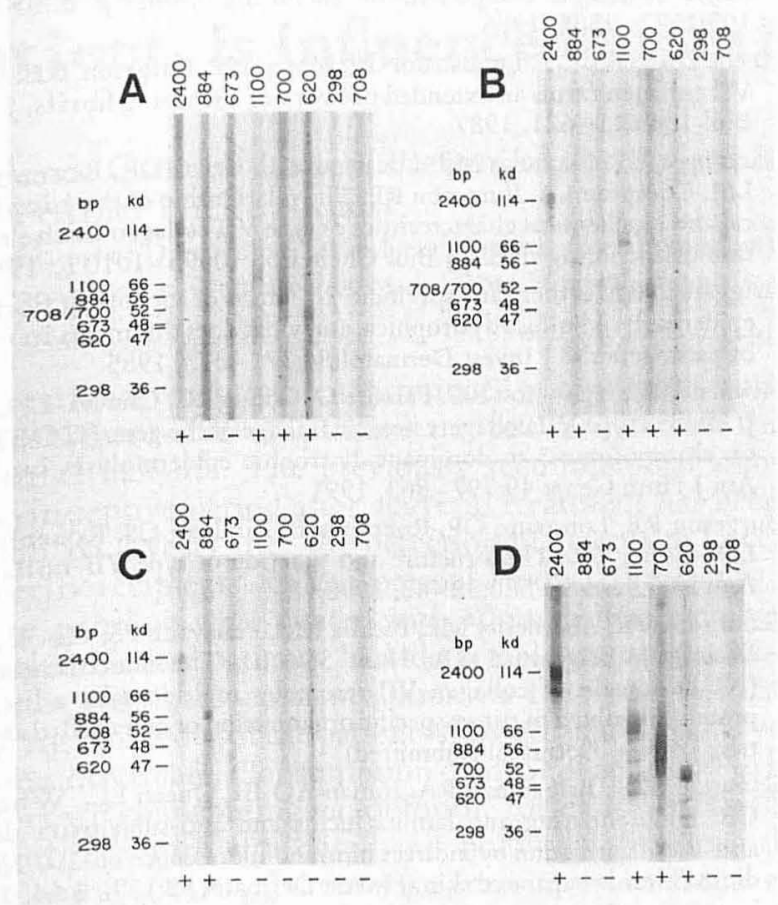

Figure 3. Representative examples of western blots of EBA and bullous SLE sera $(A-C)$, and $\mathrm{L} 3 \mathrm{~d}(D)$ against $\mathrm{pGm}$ and $\mathrm{pGx}$ fusion proteins. The lanes are labeled (left $>$ right) with the fusion protein fragments as follows: lane 1, 2400 (pGm2400); lane 2, 884 (pGx884); lane 3, 673 (pGx673); lane 4, 1100 (pGm1.1); lane 5, 700 (pGm0.7); lane 6, 620 (pGx620); lane 7, 298 ( $\mathrm{pH}$ 298); lane 8, 708 (pGx708). Refer to Fig 1 for location of fragments. The molecular weights of corresponding fragments are labeled at the left of each set of lanes A-D. Interpretation of reactivity $(+)$ or lack of theactivity $(-)$ is listed at the bottom of each lane. $A$ shows blots performed with serum from EBA patient $E-S i$. This serum only reacts with fragments containing the sequence found within the set II fusion protein, $\mathrm{pG} \times 620$. B shows blots performed with serum from EBA patient E-Su. This serum reacts with fragments containing the sequences found in set I fusion protein $\mathrm{pG} \times 884$ and the set II fusion protein pGx620. C shows blots performed with serum from bullous SLE patient, S-Re. This serum only reacts with fragments containing the set I fusion protein $\mathrm{pG} \times 884$. D shows the monoclonal antibody to the $\mathrm{NC1}$ domain of $\mathrm{C} 7, \mathrm{~L} 3 \mathrm{~d}$, only reacts with fusion proteins containing the sequences present in the set II fusion protein $\mathrm{PG} \times 620$.

1901 - 2661), by both immunoblotting and ELISA. Comparison of the immunoblotting and ELISA results (Tables II and III) showed the methods were in general agreement but the ELISA appeared to be more sensitive. Of the 79 assays in which reactivity was measured by both methods, the results agreed in 68 cases $(84 \%)$. In the remaining 11 cases, the ELISA was positive and the immunoblot was negative.

Immunoblot analysis of set I fusion proteins showed seven sera (E-Ki, E-He, E-Br, E-Su, S-Ca, S-Jo, and S-Re) recognized p Gx884, three of those sera (E-Ki, E-He, and E-Br) recognized pGx673, but none recognized $\mathrm{p} G \times 327$ (Fig 3 and Table II). By ELISA, three additional sera (E-Si, S-De, and S-Ra) reacted with pGx884 and three others (E-Su, S-Jo, and S-Re) reacted with pGx 673 (Fig 4 and Table II). Immunoblot analysis of set II fusion proteins showed 10 sera (E-Ki, E-He, E-Br, E-Si, E-Sh, S-De, S-Ca, S-Ra, S-Jo, and $\mathrm{S}-\mathrm{Re}$ ) recognized pGx1253 (Table II). Nine of those sera (all but $\mathrm{S}-\mathrm{Re}$ ) also recognized pGx620, whereas only one serum (E-Ki) recognized pGx298 (Fig 3 and Table II). By ELISA, one additional serum reacted with each of the fusion proteins (S-De with pGx298, E-Su with pGx620 and pGx1253) (Fig 4 and Table II). None of these sera reacted with pGx708 and only three sera (S-De, S-Jo, and
S-Re) reacted with pGx773 (Fig 3 and Table IV). Neither serum $\mathrm{E}-\mathrm{Te}$ nor negative control sera reacted with any of these proteins by immunoblotting or ELISA.

The reactivity of EBA and bullous SLE sera with pGx fusion proteins confirmed the results with pGm1.4 and pGm1.1 fusion proteins by showing that at least two non-overlapping regions in the NC1 domain of C7 are recognized by C7 antibodies. These results also showed that the two major epitope regions are located between the amino acids encoded by nts 327-884 and nts 16651987. The region between nts 327 and 884 consists of 186 amino acids and appears to contain more than one epitope since four sera reacted with $\mathrm{pGx} 884$ but did not react with $\mathrm{pGx673}$. This differential reactivity indicates that non-repetitive epitopes may reside in pGx673 and pGx884 and suggests that the autoantibody response to $\mathrm{C} 7$ may be antigen driven. The $3^{\prime}$ end of the second major epitope region probably lies upstream of nt 1901 rather than nt 1986 because none of the sera that reacted with this region recognized pGx708, which begins at nt 1901 . Consequently, the region may consist of 79 amino acids. Interestingly, this region was also recognized by the L3d monoclonal antibody [16].

The findings that pGx884 and pGx620 were recognized by most EBA and bullous SLE sera and that both fragments contained Fn III repeats suggested epitopes in these fragments were cross-reative. However, a comparison of amino acid sequences between those two fragments showed no regions with more than three sequential identical amino acids. Furthermore, in preliminary studies (results not shown) in which serum E-Ki was selectively absorbed on and eluted from nitrocellulose-bound purified pGx884 and pGx620, ELISA assay of the absorbed and eluted fractions showed no evidence of cross-reactivity against pGx884 and pGx620. These findings indicate that the epitopes within these fragments are distinct.

These results conclusively demonstrate that bullous SLE as well as EBA basement membrane antibodies recognize $\mathrm{C} 7$ and show both types of antibodies recognize epitopes in the region of the NC1 domain of C7 containing a series of sequential Fn III repeats. Preliminary evidence indicates multiple, distinct epitopes are recognized. None of the sera unambiguously reacted with $\mathrm{pGx} 708$, which corresponds to the potential collagen-binding A domain; however,

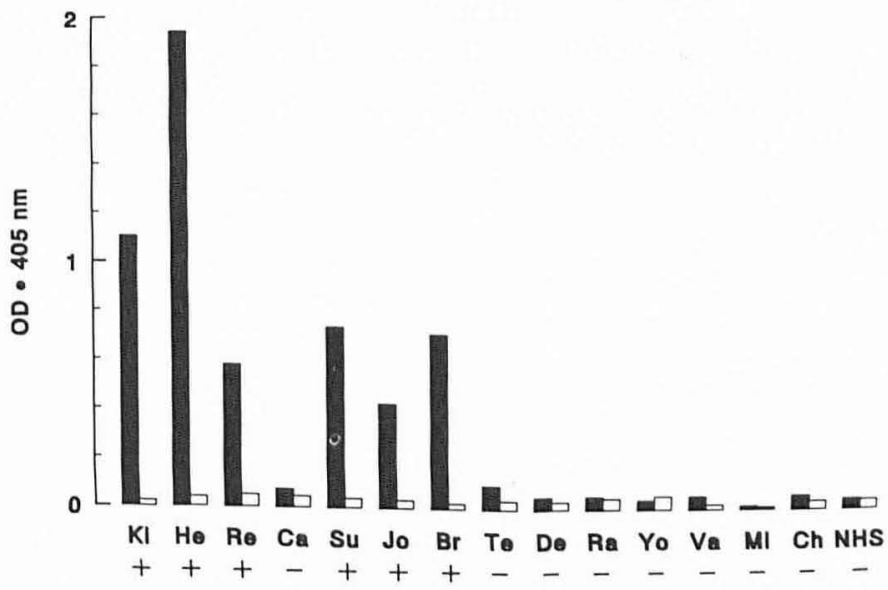

Figure 4. Results of ELISA assay of five EBA (Ki, $\mathrm{He}, \mathrm{Su}, \mathrm{Br}, \mathrm{Te})$ and five bullous SLE (Re, Ca, Jo, De, Ra) sera containing basement membrane antibodies against $\mathrm{C}$, and five control sera including two EBA sera without circulating basement membrane antibodies (Yo and Va), two bullous pemphigoid sera with antibodies to the bullous pemphigoid antigen (Ml and $\mathrm{Ch}$ ), and one normal human serum (NHS). The sera were tested against purified glutathione transferase fusion protein $\mathrm{pG} \times 673$, which is a set I fusion protein containing CVII-1 nts 1-673. EBA and bullous SLE sera were diluted $1: 20$ if the basement membrane antibody titer was less than $1: 100$. If the titer was greater than $1: 100$, they were diluted $1: 100$. All control sera were diluted $1: 20$. Closed bars, reactivity of sera with purified fusion proteins; open bars, reactivity with purified glutathione transferase. 
several sera reacted with $p G \times 1253$, which contains the $p G \times 708$ region. All but one, S-Re, of those sera reacted with the pGx620 fragment which contains sequences that are mainly $5^{\prime}$ of pGx708. The possibility that the A domain may contain autoantibody-reactive sites not detected by the methods used in these studies cannot be excluded, nor can the possibility that binding of autoantibodies to epitopes in Fn III regions secondarily influence the conformation and function of the $A$ domain be excluded. The results suggest that if autoantibodies contribute to lamina densa-dermal dysadhesion by interfering with $\mathrm{C} 7$ function, the Fn III repeats may be important to that function. No clear function for Fn III repeats in C7 has been identified, but the repeats may contribute to the conformation of the NC1 domain of C7 or possibly contribute to intermolecular or intramolecular interactions that are essential to $\mathrm{C} 7$ interactions with cells or matrix proteins. Those functions of Fn III repeats could conceivably be disrupted by autoantibodies. These results also showed a similar profile of epitope recognition by EBA and bullous SLE sera suggesting that phenotypic differences between the diseases may not be due to differences in epitope recognition $[1,2]$.

This work was supported in part by grants AR07369, AR30475, and AR10546 from the National Institutes of Health.

\section{REFERENCES}

1. Gammon WR: Epidermolysis bullosa acquisita: a disease of autoimmunity to type VII collagen. J Autoimmunity 4:59-71, 1991

2. Gammon WR, Briggaman RA: Bullous SLE: A phenotypically distinctive but immunologically heterogeneous bullous disorder. I Invest Dermatol 100:28S-34S, 1993

3. Woodley DT, Burgeson RE, Lunstrum G, Bruckner-Tuderman L, Reese MJ, Briggaman RA: The epidermolysis bullosa acquisita antigen is the globular carboxyl terminus of type VII procollagen. J Clin Invest 81:683-687, 1988

4. Gammon WR, Woodley DT, Dole K, Briggaman RA: Evidence that antibasement membrane zone antibodies in bullous eruption of systemic lupus erythematosus recognize epidermolysis bullosa acquisita autoantigen. J Invest Dermatol 84:472-476, 1985

5. Lunstrum GP, Sakai LY, Keene DR, Morris NP, Burgeson RE: Large complex globular domains of type VII procollagen contribute to the structure of anchoring fibrils. J Biol Chem 261:9042-9048, 1986

6. Parente MG, Chung LC, Ryynanen J, Woodley DT, Wynn KC, Bauer EA, Mattei M-G, Chu M-L, Uitto J: Human type VII collagen: cDNA cloning and chromosomal mapping of the gene. Proc Natl Acad Sci 88:6931-6935, 1991
7. Sakai LY, Keene DR, Morris NP, Burgeson RE: Type VII collagen is a major structural component of anchoring fibrils. J Cell Biol 103:1577 - 1586, 1986

8. Keene DR, Sakai LY, Lundstrum GP, Morris NP, Burgeson RE: Type VII collagen forms an extended network of anchoring fibrils. J Cell Biol 104:611-621, 1987

9. Bachinger HP, Nicholas MP, Lunstrum GP, Keene DR, Rosenbaum LM, Compton LA, Burgeson RE: The relationship of the biophysical and biochemical characteristics of type VII collagen to the function of anchoring fibrils. J Biol Chem 265:10095-10101, 1990

10. Briggaman RA: Is there any specificity to defects of anchoring fibrils in epidermolysis bullosa dystrophica, and what does this mean in terms of pathogenesis? J Invest Dermatol 84:371 - 373, 1985

11. Ryynanen M, Knowlton RG, Parente G, Chung LC, Chu M-L, Uitto J: Human type VII collagen: genetic linkage of the gene (COL7A1) on chromosome 3 to dominant dystrophic epidermolysis bullosa. Am J Hum Genet 49:797-803, 1991

12. Burgeson RE, Lunstrum GP, Rokosova B, Rimberg CS, Rosenbaum LM, Keene DR: The structure and function of type VII collagen. Ann NY Acad Sci 580:32-43, 1990

13. Gammon WR, Abernethy ML, Padilla KM, Prisayanh PS, Cook ME, Wright J, Briggaman RA, Hunt SW III: The noncollagenous (NC1) domain of collagen VII resembles multidomain adhesion proteins involved in tissue-specific organization of extracellular matrix. J Invest Dermatol (submitted)

14. Gammon WR, Briggaman RA, Inman AO III, Queen LL, Wheeler CE: Differentiating anti-lamina lucida and anti-sublamina densa anti-BMZ antibodies by indirect immunofluorescence on $1.0 \mathrm{M}$ sodium chloride-separated skin. J Invest Dermatol 82:139-144, 1984

15. Domloge-Hultsch N, Utecht L, James W, Yancey KB: Autoantibodies from patients with localized and generalized bullous pemphigoid immunoprecipitate the same $230-\mathrm{kD}$ keratinocyte antigen. Arch Dermatol 126:1337-1341, 1990

16. Paller AS, Queen LL, Woodley DT, Gammon WR, O'Keefe EJ, Briggaman RA: A mouse monoclonal antibody against a newly discovered basement membrane component, the epidermolysis bullosa acquisita antigen. J Invest Dermatol 84:215-217, 1985

17. Henikoff S: Unidirectional digestion with exonuclease III creates targeted breakpoints for DNA sequencing. Gene 28:351-359, 1984

18. Sambrook J, Fritsch EF, Maniatis T: In: Molecular Cloning: A Laboratory Manual. Cold Spring Harbor Laboratory Press, Cold Spring Harbor, NY, 1989

19. Sanger F, Nicklen S, Coulson AR: DNA sequencing with chain terminating inhibitors. Proc Natl Acad Sci USA 74:5463-5467, 1977

20. Voller A, Bidwell DE, Bartlett A: Enzyme immunoassays in diagnostic medicine. Bull World Health Organ 53:55-65, 1976 